\title{
Cold Flow Properties of Fatty Esters
}

\author{
Andrea KLEINOVÁ $1(\bullet)$ \\ Jarmila PALIGOVÁ 1 \\ Tomáš CVENGROŠ 1 \\ Martin CVENGROŠ 1 \\ Jozef MIKULEC ${ }^{3}$ \\ Peter ŠIMON ${ }^{1}$ \\ Ján CVENGROŠ 1
}

\section{Summary}

The article is devoted to the study of cold flow properties of neat esters of branched chain alcohols with fatty acids and blends of these esters with fossil diesel fuel. According to the determined CFPP values the influence of alcohol branching on the fuel filterability is negligible and was detected only in the case of 2-ethyl hexanol. Fossil fuel blending with fatty esters up to $10 \%$ vol. does not substantially change the cold flow properties of fossil fuel. DSC cooling scan parameters should be employed to predict CFPP of blended diesel fuel.

\section{Key words}

methyl esters, blended fuels, low temperature properties, cold filter plugging point, differential scanning calorimetry

\footnotetext{
${ }^{1}$ Faculty of Chemical and Food Technology STU, Radlinského 9, 81237 Bratislava, Slovakia $\square$ e-mail: andrea.kleinova@stuba.sk

2 Biorafinéria SK, a.s., Flámska 1, 03601 Martin, Slovakia

${ }^{3}$ Slovnaft VÚRUP, a.s., Vlčie hrdlo, 82412 Bratislava, Slovakia

Received: October 27, 2006 | Accepted: March 5, 2007
} contract No. APVV-20-037105

\section{CCS}




\section{Introduction}

Alkyl esters of higher fatty acids, especially methyl esters (FAME) and ethyl esters (FAEE) are at present considered as real alternative fuels for diesel engines. They are produced by transesterification of natural triacylglycerols - plant oils, but also animal fats - with methanol in the presence of alkali catalysts. The main advantage is that their properties are similar to those of fossil diesel fuel (DF). They are miscible with DF in any ratio, and they can be used in standard diesel engines without adjustment of the engine. The most pronounced advantages include favourable emission profile in comparison with standard fuel, the fact that they originate from domestic renewable sources, they do not increase the amount of $\mathrm{CO}_{2}$ in the atmosphere, etc. There are, however, disadvantages in comparison with standard fossil fuels, especially limited resources for their production, three to five times higher production price and less favourable low temperature properties.

The flow properties at low temperatures are one of the few controversial properties of FAME/FAEE. Unlike DF the esters have relatively high cloud point $(\mathrm{CP})$, and the pour point (PP) as well. While the $\mathrm{CP}$ and $\mathrm{PP}$ of diesel fuel are around $-15^{\circ} \mathrm{C}$ and $-27^{\circ} \mathrm{C}$ respectively, the respective values for FAME are about 15 to $25^{\circ} \mathrm{C}$ higher. The use of alkyl esters in our geographical latitudes can be seriously limited by seasonal drop of external temperatures, especially in winter period. If the temperature drop is large enough to achieve the saturation temperature of any of the FAME/FAEE components, these precipitate in the liquid mixture in the form of microscopic crystals, invisible by naked eye. At further decrease of temperature the submicrometer crystals grow further; as soon as they achieve the size of about $0.5 \mu \mathrm{m}$, they become visible. This temperature is then denoted as the cloud point. With further decrease of temperature the saturation temperatures of other components are achieved, the crystals gradually grow until they achieve the dimensions of about $0.5-1$ $\mathrm{mm}$, and they start to coalesce into sizeable agglomerates. Gradually the whole system ceases to be liquid, which is referred to as the pour point. Agglomeration of crystals occluded by the liquid phase hinders the flow of fuel through the fuel pipe and blocks the fuel filter.

Except of CP and PP, other parameters are used for evaluation of the low temperature properties of fuels, e.g. LTFT (Low Temperature Flow Test ASTM D4539) in the North America and CFPP (Cold Filter Plugging Point EN 116) in Europe. These values are more relevant than $\mathrm{CP}$ and $\mathrm{PP}$ regarding the applicability of fuels at lower temperatures. The filterability CFPP defines the lowest temperature at which at least $20 \mathrm{ml}$ of fuel passes through a $45 \mu \mathrm{m}$ mesh sieve filter with the diameter of $15 \mathrm{~mm}$ under defined conditions (time 1 minute, vacuum 200 $\mathrm{mm} \mathrm{H}_{2} \mathrm{O}$ ). CFPP is defined by melting points of individual components of mixed FAME/FAEE. The melting points are influenced by lengths of acyl chains, by the number of double bonds, by isomeric state of unsaturated groups, and by the location of double bonds. The melting point increases with increasing length of the acyl, and decreases with the number of double bonds at the same number of carbon atoms. Conjugated double bonds increase the melting point. Cis-isomers have lower melting points than the trans-isomers. Generally, the double bond represents a defect in the structure of tightly ordered layers, and therefore decreases the melting point.

In order to overcome the problems with fatty esters at low temperatures, five solutions have been proposed:

1. mixing of FAME/FAEE with conventional DF

2. use of additives - flow improvers

3. preparation of fatty esters with branched chains

4. preparation of esters with bulky substituents in the chain

5. winterisation.

Blending of FAME with fossil DF is at present the preferred and most widely used method of improvement of low temperature properties of FAME. Fossil fuel in blended fuels acts at low temperatures as a solvent of precipitated crystals, which is reflected in improved low temperature characteristics of the fuel. Published data (Dunn and Bagby, 1995) indicate that blended fuels do not exhibit significantly inferior low temperature properties in comparison with neat fossil fuel up to the content of FAME 20 vol. $\%$. The attention is paid especially to CP and CFPP. The usual blending rates FAME:DF in the North America are 20:80, and in Europe were 30:70, respectively. At the ratio of 30:70 a significant reduction of emission in the faultlessly operating engine was achieved, accompanied by slight increase of consumption ( 2 to $5 \%$ ) in comparison with neat $\mathrm{DF}$. The advantage is preparation of the mixture by simple blending of the components. According to Purcell et al. (1996) the properties of soybean oil-based FAME were as follows: cetane number $(\mathrm{CN}) 54.7$, viscosity at $40^{\circ} \mathrm{C} 3.05 \mathrm{~mm}^{2} \mathrm{~s}^{-1}$, and $\mathrm{CP}-2{ }^{\circ} \mathrm{C}$. The $\mathrm{CN}$ of DF was 43.2 ; the viscosity at $40^{\circ} \mathrm{C}$ was $2.37 \mathrm{~mm}^{2} \mathrm{~s}^{-1}$, and $\mathrm{CP}-17^{\circ} \mathrm{C}$. The blend FAME: DF 30:70 had CN 49.1; viscosity at $40^{\circ} \mathrm{C}$ was $2.84 \mathrm{~mm}^{2} \mathrm{~s}^{-1}$. The output power of the blend was by about $4 \%$ lower than that of DF, while the output power of the neat ester was by about $9 \%$ lower. The emissions of $\mathrm{CO}$ and of polycondensed aromatic compounds $(\mathrm{PAH})$ were significantly lower in comparison with $\mathrm{DF}$, the $\mathrm{NO}_{\mathrm{x}}$ emissions were comparable. According to our measurements of low temperature properties of mixed fuels containing $30 \%$ FAME from colza oil, and $70 \%$ of diesel fuel of the class $F$ (Slovnaft Bratislava), the CP, and CFPP of neat FAME were both $-8^{\circ} \mathrm{C}$, while the $\mathrm{CP}$ and CFPP of fossil fuel were $11^{\circ} \mathrm{C}$, and $-10^{\circ} \mathrm{C}$, respectively. The $\mathrm{CP}$ of the blended fuel was $-9{ }^{\circ} \mathrm{C}, \mathrm{CFPP}-10^{\circ} \mathrm{C}$ (Cvengroš, 2000). The addition of 
biogenic component did not improve the low temperature properties, but it did not impair them either.

A range of additives has been synthesised, which decrease CP and especially PP. The choice includes the viscosity modifying polymers, e.g. interpolymers containing carboxyls, copolymers styrene-maleinanhydride, polymetacrylates, polyacrylates, copolymers ethylene-vinylacetate, polyoxyalkene compounds, etc. These additives influence especially $\mathrm{PP}$, and $\mathrm{CP}$ in smaller extent. However, CP is especially important regarding low temperatures flow properties of the fuel. Some additives improving the low temperature flow properties (PP-depressants) developed for fossil fuel are effective also for FAME-based alternative fuels. They are applied at low concentrations between 0.05 and 0.2 wt. \%. The flow improvers do not influence the saturation temperature at low temperature at which the nucleation of the respective component takes place in fossil fuel and in FAME, but they influence the size and morphology of crystals, and the rate of their growth. The $\mathrm{CP}$ value is therefore altered only slightly, but the PP decreases significantly. These additives crystallise together with that component of the fuel, which is first to nucleate. The molecules of additives contain function groups, which prevent the crystal growth and agglomeration. This leads to formation of a large number of small compact needlelike particles, which form a porous filtration cake on the filter, and do not hinder the passage of the liquid phase through the filter (Dunn et al., 1996).

In the case of blended fuels with flow improvers our measurements yielded interesting results. The $\mathrm{CP}$ of fossil fuel was $-11^{\circ} \mathrm{C}$, CFPP $-10{ }^{\circ} \mathrm{C}$; the addition of $0.05 \%$ of the flow improver DF-4598 from the company LUBBRIZOL the $\mathrm{CP}$ and CFPP decreased to $-11^{\circ} \mathrm{C}$ and $-29^{\circ} \mathrm{C}$, respectively. The addition of the flow improver to FAME produced from rapeseed oil and with the $\mathrm{CP}$ and CFPP values of $-8^{\circ} \mathrm{C}$, and $-8 C^{\circ}$, respectively, resulted in no change. The addition of $0.05 \%$ of the additive LUBRIZOL DF-4598 to the mixture of $30 \%$ of FAME and $70 \%$ DF with the CP, and CFPP values of $-10{ }^{\circ} \mathrm{C}$, and $-11{ }^{\circ} \mathrm{C}$, respectively resulted in decrease of the $\mathrm{CP}$ and CFPP values of $-10^{\circ} \mathrm{C}$ and $-27^{\circ} \mathrm{C}$, respectively (Cvengroš, 2000). In another set of measurements (Bírová et al., 2003) with flow improvers the CFPP value of studied FAME from used cooking oils was $+1{ }^{\circ} \mathrm{C}$. The CFPP of diesel fuel was $-5^{\circ} \mathrm{C}$, and the CFPP of the mixture of $31.8 \%$ FAME, $67.5 \%$ DF, and $0.7 \%$ of LUBOFLOW 3101 was $-16^{\circ} \mathrm{C}$. The addition of $0.3 \%$ of LUBOFLOW 3111, the flow improver developed specially for the use with FAME from rapeseed oil, decreased the CFPP from the original value $-10^{\circ} \mathrm{C}$ down to $-21^{\circ} \mathrm{C}$ (Cvengroš, 2004).

Another possibility of influencing the low temperature properties of fatty esters is the synthesis, which builds a bulky substituent into the chain, on a double bond of an acyl, for example. A hypothesis exists that the bulky sub- stituent disrupts the harmony during the solid phase formation, and the orientation in one direction.

Similar effect is observed also with the use of secondary isopropyl- and isobutyl alcohols for the preparation of esters. According to Lee (1995) the esters based on these alcohols and soybean oil-based FFA exhibit the onset temperatures from DSC (differential scanning calorimetry) measurements by 7 to $11^{\circ} \mathrm{C}$ and 12 to $14^{\circ} \mathrm{C}$ lower for isopropyl- and 2-butyl esters, respectively. Simultaneously, decreased values of CP and PP were recorded. However, due to economic reasons (higher price of isoalcohols), the possibilities in this respect are rather limited.

Winterisation removes the solid fraction formed by cooling of esters by filtration, and the liquid fraction of predominantly unsaturated compounds then exhibits lower $\mathrm{CP}$ and PP. Winterisation removes especially saturated fatty esters with higher $\mathrm{CN}$, and the $\mathrm{CN}$ of the residual mixture decreases. The onset temperature of FAME made of soybean oil has been decreased this way from $+3.7^{\circ} \mathrm{C}$ to $-7.1{ }^{\circ} \mathrm{C}$, but the yield was low $(26 \%)$ (Lee, 1995). The used solvent has a marked influence on the process. The process is energetically demanding (cooling). However, in our country the natural cold in winter season can be utilised, the tanks with fuel can be stored outside, and the solid fraction can be used as the fuel in summer. The problem is low yield, around $33 \%$, due to large occlusion of crystals with the liquid. Treatment of FAME with PP-depressants before winterisation decreases occlusion of crystals with the liquid phase, and thus increases the yield.

Our tests of FAME from used frying oils without modifications showed CFPP value of +2 to $-2{ }^{\circ} \mathrm{C}$, and $-6{ }^{\circ} \mathrm{C}$ after addition of $0.7 \%$ LUBOFLOW $3115 \mathrm{~F}$ to the original FAME. The CFPP value equal to $-8^{\circ} \mathrm{C}$ was achieved after winterization of the original FAME at $-5^{\circ} \mathrm{C}$ with the recovery rate of $88 \%$. The CFPP value after winterization and addition of LUBOFLOW $3115 \mathrm{~F}$ was $-14^{\circ} \mathrm{C}$ (Cvengroš et al., 2004).

Phase changes taking place in fuels at low temperatures can be studied by DSC (differential scanning calorimetry) with advantage. DSC is the thermo-analytical method where the difference of the heath flow between the sample and the reference, and its dependence on the temperature and time are measured. According to Heino (1987) the DSC allows determination of CP of fuels more precisely than standard procedures known from the analysis of fuels. Claudy et al. (1986) uses the onset temperature from the DSC cooling scan for determination of CP, PP, and CFPP of fossil fuels without additives. Dunn (1999) successfully applied DSC for evaluation of CP, PP, and CFPP of FAME from soybean oil, from beef fat (tallow), and of their mixtures with and without depressants. After statistical evaluation of data they found simple linear de-

\section{CCS}

Agric. conspec. sci. Vol. 72 (2007) No. 3 
pendences between CP, or CFPP and the temperatures of characteristic intervals at DSC scans.

The aim of the presented study is to evaluate the influence of the presence of branched chains of isoalcohols on flow properties of fatty esters at low temperatures. Both pure esters and esters mixed with fossil fuel have been studied. Except of standard determination of CFPP values, some samples were evaluated also by DSC, in order to identify the relations between low temperature parameters of esters, and the parameters acquired from DSC measurements.

\section{Materials and methods}

For the measurements we used ethyl esters of sunflower oil with increased amount of oleic acid, ethyl- and methyl esters of castor oil, and isopropyl esters, 2-butyl esters and 2-ethyl hexyl esters of technical-grade oleic acid. The share of acyls (acid profiles) of the respective sources of fatty acids are shown in the Table 1 . The acid profile has been determined by GLC chromatography. The castor oil is characterized by dominant share $(80-90 \%)$ of ricine oleic acid (12-hydroxy octadecene acid C18:1, OH).

Esters of the technical oleic acid were prepared in the standard way by acid catalyzed esterification of the acid using a suitable alcohol. The esters on the basis of sunflower oil and castor oil were prepared by alkali catalyzed transesterification of the oil using methanol or ethanol. Raw esters were finally treated with molecular distillation on a short-path evaporator (Cvengroš, 1990).

The summer diesel fuel without additives from Slovnaft Inc. Bratislava was used as the standard diesel fuel. The filterability CFPP was determined according to the STN EN 116 . The uncertainty of the measurement was $\pm 0.5^{\circ} \mathrm{C}$.

The DSC measurements were carried out by using the differential scanning calorimeter Shimadzu DSC-60. The temperature range was between -50 to $+30^{\circ} \mathrm{C}$. Cooling and heating runs were recorded, where the rates of cooling/ heating were $1,3,5,7,10$ and $15 \mathrm{~K} / \mathrm{min}$. The temperature calibration was carried out to the melting points of water and In. Enthalpic calibration was carried to the melting enthalpy of In. Samples of 3-5 mg were placed in sealed aluminium pans. The purge gas was nitrogen; its flow rate was $50 \mathrm{ml} / \mathrm{min}$.

\section{Results and discussion}

The filterability values CFPP of pure esters and of their mixtures (5 and 10 vol. \%) with summer diesel fuel are shown in the Table 2. Table 2 shows also the CFPP values of the used reference fossil diesel fuel - summer diesel fuel.

The data shown in the Table 2 indicate that branching of the alcohol chain does not influence the filtration abil- ity of pure esters significantly. For comparison, the CFPP values of FAME from rapeseed oil range between -9 and $-12^{\circ} \mathrm{C}$. The only exceptions are the 2-ethyl hexyl esters from the technical oleic acid, where notably low value of CFPP was achieved. Ethyl esters from sunflower oil have, in spite of high content of unsaturated oleic acid, relatively high CFPP. According to literature FAME from the classical sunflower oil have the CFPP value even higher, $-2{ }^{\circ} \mathrm{C}$ (Peterson et al., 1987).

The data on filterability of methyl- ethyl esters of castor oil have not been published yet. There is effort to utilize this natural product for fuel applications in Brazil. Some of the properties of castor oil-based FAME/FAEE are not favourable The density of castor oil FAME $\left(924.4 \mathrm{~kg} \mathrm{~m}^{-3}\right)$ and that of FAEE $\left(914.3 \mathrm{~kg} \mathrm{~m}^{-3}\right)$ are higher than the limit of $900 \mathrm{~kg} \mathrm{~m}^{-3}$ at $15^{\circ} \mathrm{C}$ defined by the standard EN 14214 . The viscosity of castor oil FAME $\left(13.34 \mathrm{~mm}^{2} \mathrm{~s}^{-1}\right)$ and that of FAEE $\left(13.87 \mathrm{~mm}^{2} \mathrm{~s}^{-1}\right)$ at $40{ }^{\circ} \mathrm{C}$ are more than double then the limit value of $5.00 \mathrm{~mm}^{2} \mathrm{~s}^{-1}$. The possible solution to the problem of the high viscosity and density of the esters can be their blending with conventional diesel fuel. The CFPP values of neat castor oil-based FAME/FAEE are relatively high.

The presented data indicate that the attempts to decrease CFPP, and thus to improve low-temperature flow properties of fatty esters with the use of branched alcohols are not effective. Despite some optimistic data in literature (Foglia et al., 1997), both the presented results and the unpublished results of our previous measurements show that no significant decrease of the CFPP value of esters with branched alcohols could be achieved in comparison with FAME. Moreover, the economic reasons are also important: lower iso-alcohols are notably more expensive than methanol.

In the second part of the Table 2 the CFPP values of the mixtures of 5 and $10 \%$ of appropriate fatty esters with standard DF are shown. It is interesting that the addition of $10 \%$ of fatty esters practically does not influence the CFPP value of the mixed fuel regardless to the origin and structure of the acyl or the alcohol chain. This result can have significant impact on law-making activities aimed at the evaluation of the significance of the CFPP criterion for neat FAME/FAEE determined for use in blends with the fossil diesel fuel. In this respect the CFPP of neat FAME/ FAEE does not have to be of interest, if the required CFPP of the blended fuel is achieved by suitable flow improvers. Tendency to utilize blended fuels with low ratio of biogenic component up to $5 \%$ (for example, in Austria obligatory addition to the fossil fuel is $3 \%$ FAME) is supported also by the legislation; the presence of components up to $5 \%$ does not require further comments. At such low ratio FAME/FAEEs their low-temperature properties practically do not influence the parameters of blended fuel. This way 
Table 1. Acid profile of used fatty acid sources (area \%, GLC)

\begin{tabular}{|c|c|c|c|c|c|c|c|}
\hline FA source & $\mathrm{C} 14$ & $\mathrm{C} 16$ & $\mathrm{C} 18: 0$ & $\mathrm{C} 18: 1$ & $\mathrm{C} 18: 2$ & $\mathrm{C} 18: 3$ & $\mathrm{C} 20: 0$ \\
\hline High-oleic sunflower oil & - & 9.9 & 1.6 & 78.9 & 15.6 & 0 & - \\
\hline Castor oil & 1.0 & 9.4 & - & 89.1 & - & - & 0.5 \\
\hline Industrial oleic acid & - & 9.8 & 2.9 & 61.2 & 23.0 & 2.2 & 1.0 \\
\hline
\end{tabular}

Table 2. CFPP values of prepared fatty esters

\begin{tabular}{lccc}
\hline Fatty esters & & CFPP, ${ }^{\circ} \mathrm{C}$ \\
\cline { 2 - 4 } & Neat esters & Esters+DF 5:95 & Esters+DF 10:90 \\
Isopropyl esters of industrial oleic acid & -10 & -8 & -8 \\
2-butyl esters of industrial oleic acid & -9 & -8 & -9 \\
2-ethyl hexyl esters of industrial oleic acid & -23 & -9 & -9 \\
Ethyl esters of high-oleic sunflower oil & -4 & -8 & -8 \\
Methyl esters of castor oil & -1 & -8 & -8 \\
Ethyl esters of castor oil & -1 & -9 & -8 \\
\hline Summer diesel fuel & -8 & - & - \\
\hline
\end{tabular}

Table 3. CFPP and onset temperatures of selected fatty esters

\begin{tabular}{lccc} 
Fatty esters & CFPP, ${ }^{\circ} \mathrm{C}$ & Onset t, ${ }^{\circ} \mathrm{C}$ (grad. $\left.5 \mathrm{~K} / \mathrm{min}\right)$ & Onset t, ${ }^{\circ} \mathrm{C}$ (grad. $7 \mathrm{~K} / \mathrm{min}$ ) \\
Ethyl esters of castor oil + DF 10:90 & -8 & -8.8 & -9.0 \\
Ethyl esters of high-oleic sunflower oil + DF 10:90 & -8 & -9.3 & -9.5 \\
2-ethyl hexyl esters of industrial oleic acid + DF 10:90 & -9 & -7.8 & -9.2 \\
\hline Summer diesel fuel & -8 & -9.6 & -10.1 \\
\hline
\end{tabular}

FAME/FAEE from animal fats and from used frying oils with high CFPP could be used.

For DSC study a set of samples of blended fuels DF + ester component was selected. The DSC measurements were performed at various heating and cooling rates with the aim to find the optimum mode. The DSC onset temperatures decreased slightly with increasing of cooling rates. The best agreement between CFPP parameters and DSC onset temperatures was reached at cooling rates between 5 and $7 \mathrm{~K} \mathrm{~min}^{-1}$. Cooling scan parameters gave the most accurate correlations between DSC values and low-temperature flow properties of methyl esters studied in this work. The results obtained at these two optimum cooling rates are shown in the Table 3.

The comparison of the onset temperatures and CFPP values shows that good agreement was achieved. The onset temperature values from DSC scans are very close to CFPP figures. Results of Dunn (1999) with the linear correlation between the CFPP and onset temperature with some shift on y-axis can be connected with different temperature gradient. The slope for our and Dunn's measurements is equal.

DSC records show multiple peaks in cooling runs for neat DF and blended fuel containing branched-chain al- cohol 2-ethyl hexanol. This indicates the formation of the polymorphs in these fuels.

DSC cooling scan parameters should be employed to predict CFPP of blended diesel fuel. The relative diversity among the acyl and alkyl structures of the esters studied indicates that the DSC analyses may be applied to methyl esters derived from various feedstocks.

\section{References}

Bírová A., Radovanović D. Šimon P., Cvengroš J. (2003): Comparison of Methyl Esters Low-Temperature Measurements with CFPP Method. Proc. $41^{\text {st }}$ Int. Petroleum Conference, October $6^{\text {th }}-8^{\text {th }}, 2003$, Bratislava, 10 pp.

Claudy P.,Létoffé J.M., Neff B., Damin B. (1986): DSC cooling scan parameters Diesel fuels: determination of onset crystallization temperature, pour point and filter plugging point by differential scanning calorimetry. Correlation with standard test methods. Fuel 65, 861-864.

Cvengroš J. (1990): Laboratórne molekulové odparky. Chem. Prum. 40, 135-140.

Cvengroš J., Považanec F. (1996): Production and Treatment of Rapeseed Oil Methyl Esters as Alternative Fuels for Diesel Engines. Biores. Technol. 55, 145-152. 
Cvengroš J (2000): Nízkoteplotné vlastnosti palív na báze metylesterov vyšších mastných kyselín. Proc. Conf. "Požadavky na kvalitu motorového paliva na bázi methylesterů řepkového oleje”, TECHAGRO 2000, 5.4.2000, Brno, Czech Republic.

Cvengroš J., Radovanović D., Mikulec J. (2004): Oxidation stability and low-temperature properties of methyl esters based on used edible oils and fats. Proc. XII International Scientific Conference "Progress in Technology of Vegetable Fats", 31.05.02.06.2004, Pieštany, 7 pp.

Dunn R.O., Bagby M.O. (1995): Low-Temperature Properties of Triglyceride-Based Diesel Fuels:transesterified Methyl Esters and Petroleum Middle Distillate/Ester Blends.J. Amer. Oil Chem. Soc. 72, 895-904.

Dunn R.O., Shockley M.W., Bagby M.O. (1996): Improving the Low-Temperature Properties of Alternative Diesel Fuels: Vegetable Oil-Derived Methyl Esters. J. Am. Oil Chem. Soc. 73 1719-1728.

Dunn R.O. (1999): Thermal Analysis of Alternative Diesel Fuel from Vegetable Oil. J. Am. Oil Chem. Soc. 76, 109-115.
Foglia T.A., Nelson L.A., Dunn R.O., Marmer W.N. (1997): LowTemperature Properties of Alkyl Esters of Tallow and Grease. J. Amer. Oil Chem. Soc. 74, 951-955.

Heino E.L. (1987): Determination of cloud point for petroleum middle distillates by DSC. Thermochim. Acta 114, 125-130.

Lee I., Johnson L.A., Hammond E.G. (1995): Use of BranchedChain Esters to Reduce the Crystallization Temperature of Biodiesel. J. Am. Oil Chem. Soc. 72,1155-1160.

Lee I., Johnson L.A., Hammond E.G. (1996): Reducing the Crystallization Temperature of Biodiesel by Winterizing Methyl Soyate. J. Am. Oil Chem. Soc. 73, 631-636.

Peterson C.L., Korus R.A.,Mora P.G., Madsen J.P. (1987): Fumigation wit Propane and Transestrerification Effects on Injector Coking with Vegetable Oils. Trans. ASAE 30 28-35.

Purcell D.L., McClure B.T., McDonald j., Basu H.N. (1996): Transient Testing of Soy Methyl Ester Fuels in an Indirect Injection, Compression Ignition Engine. J. Am. Oil. Chem. Soc.73, 381-388.

acs72_28 